This document is the accepted manuscript version of the following article:

wigger, H., Woht1eben, W., \& Nowack, B. (2018). Redefining environmenta1

nanomaterial flows: consequences of the regulatory nanomaterial definition on the results of environmental exposure models. Environmental Science: Nano, 5(6), 1372-1385. https://doi.org/10.1039/C8EN00137E

\title{
Redefining environmental nanomaterial flows: Consequences of the regulatory nanomaterial definition on the results of environmental exposure models
}

Henning Wigger ${ }^{1 *}$, Wendel Wohlleben ${ }^{2}$, Bernd Nowack ${ }^{1}$

1) Empa, Swiss Federal Laboratories for Materials Science and Technology, Technology and Society Laboratory, Lerchenfeldstrasse 5, 9014 St. Gallen, Switzerland

2) BASF SE, Dept. Material Physics, RAA/OR - B7, Carl-Bosch-Strasse 38, 67056 Ludwigshafen am Rhein, Germany

${ }^{*}$ Corresponding author

Contact: henning.wigger@googlemail.com

Wigger, H.; Wohlleben, W.; Nowack, B. (2018) Redefining environmental nanomaterial flows: Consequences of the regulatory nanomaterial definition on the results of environmental exposure models. Environ. Sci. Nano 5: 1372-1385.

DOI: $10.1039 /$ c8en00137e 


\begin{abstract}
All nanomaterial exposure estimates require fundamentally knowledge about the production volumes of the nanomaterials. Published values of production volume can vary by orders of magnitude, mainly caused by ambiguities in the definition of what a nanomaterials actually is. The recommendation for a definition of "nanomaterials" by the European Commission has to some extent clarified this issue. In the meantime, first data are available for registered production volumes of nanomaterials in France based on a mandatory registration scheme. We have compared the tonnages of registered production and import of substances in nanoform in France with the estimated total market volumes of this substance, which includes both non-nano-forms (bulk) and nanoforms. These substances comprised $\mathrm{CaCO}_{3}$, carbon black, $\mathrm{TiO}_{2}, \mathrm{SiO}_{2}, \mathrm{ZnO}$, AZO-based and diketo-pyrrolo-pyrrole-based (DPP) pigments as well as carbon nanotubes. The results show that some materials such as $\mathrm{SiO}_{2}$ and DPP have a good match between reported nanoform and total production volumes, whereas for other materials such as $\mathrm{TiO}_{2}$ and $\mathrm{ZnO}$ the reported nanoform production volumes are only a fraction of total production volumes. This means that for $\mathrm{SiO}_{2}$ and DPP the "conventional form" and the nanoform are identical, while $\mathrm{TiO}_{2}$ and $\mathrm{ZnO}$ have been used as bulk materials in several applications. With this knowledge that for $\mathrm{SiO}_{2}$ the global production of "conventional" silica is in fact all nano-silica, we can apply the information on the uses of conventional silica to refine the material flow model for nano-silica. The results of this updated modeling show an input mass flow of (nano)silica to environmental compartments that is four to five times larger than previously modelled. The flows to natural and urban soils even increased by a factor of 13 , because not only the production but also single specific applications (such as the use in tires) may have a considerable impact on the environmental exposure. Future environmental risk assessments ought to prioritize both by production volume and/or by the probability of direct environmental releases, considering that data on conventional substances may often represent forms of the substances that are nanomaterials in terms of the definition that is recommended by the European Commission.
\end{abstract}

Keywords: silica, nanomaterials, regulation, definition, material flow analysis, production volume, environmental concentrations 


\section{Graphical abstract}

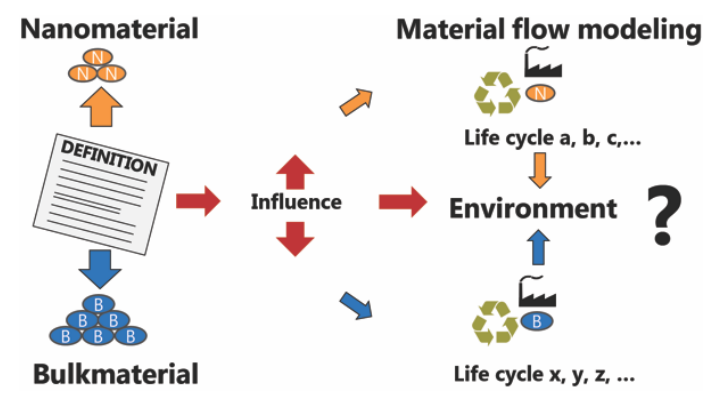

This article shows the influence of the nanomaterial definition on the mass transfers of nanomaterials into the environment. 


\section{Introduction}

Engineered nanomaterials (ENM) enable the performance of nano-enabled products (NEP) that would not be achieved with non-nano-forms of the same substance ${ }^{1}$. ENM are applied in various industry segments and product categories ${ }^{2,3}$. ENMs may end up in environmental compartments depending on their use in industrial and consumer products ${ }^{4-6}$. The environmental exposure assessment attempts to tackle this challenge by providing estimations on the mass flows to the environment and quantifying the predicted environmental concentrations (PEC) in the respective compartments ${ }^{7}$. Since the validation in the real world is still challenging, environmental material flow models were developed in order to give first estimations on potential environmental release of ENMs ${ }^{8}$. Such models are based on a massbalance approach in which the input and output flows of a defined area (i.e. system) are investigated. The models can be designed by either simple equations ${ }^{9}$, particle or material flow models ${ }^{5,10,11}$ or probabilistic material flow models ${ }^{12-14}$, considering different degrees of uncertainty in the model calculation. The models differ also in the amounts of considered applications ranging from single applications ${ }^{15}$ to the whole application field of the ENM in question ${ }^{6}$. In recent years first dynamic models were also developed to address the temporal variability of environmental releases to consider potential hot spot releases over a period of time ${ }^{16-20}$.

The two major influencing parameters of all environmental release and exposure models are the estimated production volume and its allocation to the product categories in which ENMs are supposed to be incorporated to a specific amount and form ${ }^{4}$. Generally, the information on both parameters are often missing or not accessible due to confidentiality. Consequently in the past ten years, several approaches and modeling studies were published that used best-guesses or estimates based on interviews, surveys and/or market reports to quantify the potential production volumes ${ }^{21,22}$. Another complication arises from the heterogeneous scope of nano-specific estimates, which may restrict their scope to materials with unique and novel properties, or may set an arbitrary date (often the year 2000) to define novelty on the market. It is thus not surprising that estimates for production volumes of ENMs cover a broad range ${ }^{8,23}$. For instance, for CNTs the estimated production volume ranges from 31 to 1 '224 metrics tons in Europe in the year $2012^{6}$. The spread is even higher for materials that have both conventional and innovative nanoforms, such as nano-silica: estimates range from 17.5 to $245^{\prime} 000$ metric tons in Europe ${ }^{24}$. Particularly, market reports have shown a higher variability depending on the publishing organization. These market reports are usually compiled via interviews of experts (i.e. companies willing to give their insight), reflecting also the market expectations of companies. The sizebased definition of nanomaterials recommended by the European Commission (EC) for regulatory purposes ${ }^{25}$, eliminates ambiguity of perspective on novelty or uniqueness, because the scope is defined only by measurable parameters ${ }^{26-29}$.

Based on the EC recommended definition, regulatory bodies in Norway ${ }^{30}$, Belgium ${ }^{31}$, Denmark ${ }^{32}$ and France ${ }^{33}$ have introduced mandatory registration schemes for nanomaterials and/or NEPs. Belgium, Denmark and France annually publish an aggregated version of the registered ENMs and/or NEPs. The French report summarizes the registered production volumes for single ENMs, which should reflect the real French market but without considering imported NEPs. In the context of environmental exposure assessments, this data has not been implemented in models so far. 
Another important parameter for the modeling of environmental exposure to ENMs are the product categories where the ENM are used in. These categories are characterized by different release profiles depending on the application, ENM incorporation into a matrix ${ }^{34}$ and the exposure to physcial and/or chemical stresses ${ }^{35}$. It is known that the product application determines the starting points of releases, which can be strongly dependent on the product use and design ${ }^{36}$. Information on potential ENM applications are either usually only voluntarily collected or are recorded by regulatory bodies often without enabling public access or in an aggregated form ${ }^{37}$. An exception are cosmetics (and soon novel foods) which have to be labeled in the European Union when containing nanomaterials.

For the identification of the nano-applications four approaches have been applied so far: 1. Internet queries and therein the fractioning of product categories according to the query hits, 2. patent databases, 3. market reports and 4 . voluntary nanoproduct databases. These methods identified many applications that mainly include titanium dioxide and silver nanoparticles. This has led to the misleading perception that personal care products and biocidal applications would dominate the use categories of nanomaterials. Other materials were considerably less often mentioned ${ }^{37,38}$. The reason for this bias likely is that only specific nanomaterial properties are advertised and consequently can be identified as products containing nanomaterials. Other products that may contain ENMs but do not exhibit advertisable material properties are neglected in these approaches ${ }^{37}$. Also, product categories are often quite vaguely defined such as the "automotive" category, that includes different kinds of applications having different releases profiles during use and end-of-life processes ${ }^{39}$.

The required data on production volumes and product category allocation are only available separately - if at all - and a link between both would be needed for improved environmental exposure modelling. On the other hand, data are available about production volumes of specific substances (often differentiated by grades for specific applications, which in turn may correlate with specific nanoforms and nonnano-forms) such as in official registries, market reports or estimations in the scientific literature. Since it has been questioned if something like "nano-silica" really exists as a new entity or if it is just re-naming the existing silica ${ }^{40}$, model designers could draw on conventional data on produced amounts and product categories when bulk materials and nanomaterials are the same.

The goal of this paper was thus to critically examine the production volumes listed in the French nanoregistry $33,41,42$ and compare it to known production volumes of total or "conventional" materials. Based on this comparison, we selected nano-silica as a case study and developed a new material flow model for nano-silica that incorporates the knowledge on the production and use of "conventional silica". 


\section{Methods}

The overall approach for redefining the production volume and product categories of (nano)silica was based on a two-tiered approach. First, the available data of the French repository were analyzed with regard to ENMs. Second, market reports providing data on all forms of a specific material, that generally include a product use categorization of substances, were compared to the French quantities reported. If both reported numbers would match, the corresponding data on production and product use categories can be used to improve the model of the ENM in question. In the following the approach for both data sources will be described. Potential limitations of this approach will be addressed in the discussion section.

\section{Production volume}

The production volume estimation was redefined by using data of the French repository on nanomaterials ${ }^{33}$. Since 2013 the French government mandatorily requires a registration of nanomaterials that are produced or imported (only nanomaterials as substances, not articles that contain nanomaterials, nor final nano-enabled products) into France. These numbers were collected and prepared regarding the considered nanomaterial using the reference year 2013 in France. We have chosen the year 2013 and not the following years because only in the first year actual tonnages were reported, in later years only a range with a factor 10 was provided. Although the number of registered substances and tonnages varied in the following years, the absolute values of the ENMs considered in this study can be applied for the estimation of the production volume. We checked that the exact numbers of 2013 for the ENMs considered remain compatible with the ranges reported for 2015 as well as 2016, and found no discrepancies in the French registry ${ }^{33,41,42}$.

Generally, all nanomaterials were reported as a single entity in the French registry, but in some cases entries were registered several times with different names such as, for instance, color pigment Red 101 and iron oxide $\mathrm{Fe}_{2} \mathrm{O}_{3}$. For these materials, the total numbers were determined by summing up the reported numbers for the basic chemical composition and/or the color name.

Second, we have used several market data reports for the respective substance in order to retrieve the amount of all forms of this substance, anticipating that it includes both nanoforms and non-nano-forms, both conventional and novel grades ${ }^{43-50}$. Importantly, it has to be noted that these reports do not differentiate nano- and non-nanomaterials, but they report the overall produced amount per substance at a global and/or regional scale. For comparing the numbers on a national scale, we have down-scaled the given numbers by multiplying the globally produced amount with the French share of the gross world product (GWP) in 2013. The share of the French gross domestic product (GDP) approximately accounted for $3.7 \%$ in 2013 of the GWP 51 .

Finally, the production volume of the market report for silica was considered at an European level, which had an acceptable fit of both data sources. Of course, this approach may have some limitations that will be addressed in the discussion section.

\section{Product categories and allocation of the production volume}


For nano-silica a new distribution of the produced mass to product categories was made. Compared to the state-of-art modeling of nano-silica ${ }^{24}$, we adjusted and allocated the product categories to those of conventional silica. Compared to the state-of-the-art, this categorization is more extensive in terms of the number of categories and thereby in the level of detail. While in the former model approximately 20 application categories were considered ${ }^{24}$, we included 30 categories based on a recent market report 45. In that way our approach is similarly detailed as that of Giese et al. ${ }^{18}$, who considered an older published categorization scheme. 
Table 1. Allocation of the production and consumption volume to different conventional product categories of different silica forms in 2013. The distribution is based on the market report on silica compiled by Glauser et al. $(2014)^{45}$.

\begin{tabular}{|c|c|c|c|c|}
\hline & $\begin{array}{l}\text { Production } \\
\text { Western Europe } \\
\text { [metric ktons] }\end{array}$ & $\begin{array}{l}\text { Consumption } \\
\text { [metric ktons] }\end{array}$ & $\begin{array}{l}\text { Fraction in } \\
\text { category }\end{array}$ & $\begin{array}{l}\text { Overall } \\
\text { fraction }\end{array}$ \\
\hline Precipitated silica* & 370 & 347 & & 0.6884 \\
\hline Elastomers & & 220 & 0.6340 & 0.4120 \\
\hline Detergents and cosmetics & & 30 & 0.0865 & 0.0562 \\
\hline $\begin{array}{l}\text { Carrier materials (fertilizer or ag- } \\
\text { ricultural soil application) }\end{array}$ & & 26 & 0.0749 & 0.0487 \\
\hline Polymers and plastics & & 25 & 0.0720 & 0.0468 \\
\hline Sealants & & 16 & 0.0461 & 0.0300 \\
\hline Paints, coatings and ink & & 15 & 0.0432 & 0.0281 \\
\hline Other & & 16 & 0.0461 & 0.0300 \\
\hline Colloidal silica* & 26.1 & 21.1 & & 0.0419 \\
\hline Refractory binders & & 3.8 & 0.1801 & 0.0071 \\
\hline Investment casting & & 3.5 & 0.1659 & 0.0066 \\
\hline Pulp and paper & & 4.6 & 0.2180 & 0.0086 \\
\hline Electronics & & 3.8 & 0.1801 & 0.0071 \\
\hline Beverage clarification & & 1.8 & 0.0853 & 0.0034 \\
\hline Textile processing & & 1.7 & 0.0806 & 0.0032 \\
\hline Other & & 1.9 & 0.0900 & 0.0036 \\
\hline Silica gel ${ }^{*}$ & 26.9 & 32.1 & & 0.0637 \\
\hline Beer fining & & 9.6 & 0.2991 & 0.0180 \\
\hline Other food & & 1.3 & 0.0405 & 0.0024 \\
\hline Adsorbents and Desiccants & & 7.4 & 0.2305 & 0.0139 \\
\hline Paints and coatings & & 4.8 & 0.1495 & 0.0090 \\
\hline Plastics and textiles & & 2.6 & 0.0810 & 0.0049 \\
\hline Pharmaceutical tableting & & 2.5 & 0.0779 & 0.0047 \\
\hline Dentrifices & & 0.6 & 0.0187 & 0.0011 \\
\hline Other & & 3.3 & 0.1028 & 0.0062 \\
\hline Fumed silica* & 66 & 58.9 & & 0.1168 \\
\hline Silicone elastomers & & 26.2 & 0.4448 & 0.0491 \\
\hline other silicones & & 4.7 & 0.0798 & 0.0088 \\
\hline Paints and coatings & & 7.4 & 0.1256 & 0.0139 \\
\hline Polyester resins & & 5.6 & 0.0951 & 0.0105 \\
\hline Adhesives and sealants & & 4.1 & 0.0696 & 0.0077 \\
\hline Epoxy resins & & 3.8 & 0.0645 & 0.0071 \\
\hline Industrial inks & & 2.6 & 0.0441 & 0.0049 \\
\hline Other & & 4.5 & 0.0764 & 0.0084 \\
\hline Total & 489 & 459.1 & & 1 \\
\hline
\end{tabular}

*The bold categories represent the summed up subcategories in the rows below. 


\section{Material flow modeling}

The applied probabilistic material flow modeling (PMFA) approach was originally developed by Gottschalk et al. ${ }^{52}$ and specifically applied by Wang et al. ${ }^{24}$ to nano-silica. The PMFA is based on massbalance equations assuming steady-state equilibria for each compartment considered. Every input and output flow (determined by transfer coefficients) is modeled as triangular probability distributions, which were derived by a Monte-Carlo Simulation with a 100'000 times repeated calculation within a range of \pm 50 percentage of every modal value. By doing so, the inherent uncertainty of each value is regarded by the corresponding probability distribution.

The model purpose was to identify the influence of the selected production volume (nano vs. bulk) and product categories on the environmental releases and the estimated environmental concentrations in a worst-case. The system boundary was set to Europe for comparing our results with the published data. The model structure consists of nineteen compartments that are interlinked by mass flows. The compartments are differentiated into technical and environmental compartments. The former includes all technical facilities such as wastewater treatment plants (WWTP), waste incineration plants (WIP), landfills, biowaste, cement kilns and export as well as the recycling/waste management system (WMS). The environmental compartments consider natural compartments such as air, soil (direct release to urban and natural soil and sludge treated soil), surface waters and sediments. The compartments landfill, biowaste, cement kiln, recycling/WMS, soil and sediments are defined as sinks, in which no further transformations or environmental transfers were assumed. The environmental fate and behavior of environmentally released ENMs is not considered in this model. All reported results of this study should be interpreted as worst-case knowing that silica will undergo several transformations once being released to an environmental compartment (cf. discussion section).

Consequently, the results should serve as an indication for relevant material flows and can be seen as a starting point for environmental fate models which are much more specialized than (P)MFA models. The amounts in water and sediments are provided for two mutually exclusive scenarios: either full stability in water or complete sedimentation. Therefore, the reported flows and predicted environmental concentrations (PEC) for water (i.e. before sedimentation) and sediment (i.e. after sedimentation) represent worst-case assumptions. The air compartment was calculated with a deposition to soil and water compartment within ten days similar to particulate matters as done by Sun et al. ${ }^{13}$. Hence, the worstcase concentration for the air compartment considers a reduced residing mass with a factor of 10/365 (cf. Sun et al. ${ }^{13}$ ). The volumes of the environmental compartments are based on the calculation of Sun et al. ${ }^{13}$ and Wang et al. ${ }^{24}$ assuming well-mixed compartments on a regional scale. 


\section{Transfer coefficients for technical and environmental compartments}

Transfer coefficients define the input and output flows for each compartment. The model structure (i.e. the number and relation of compartments) and the applied transfer coefficients were based on the former work by Wang et al. ${ }^{24}$, who compiled transfer coefficients for nano-silica based applications. Based on the assumptions made by Wang et al. ${ }^{24}$, our study implemented their transfer coefficients only if the product categories matched. Otherwise we adjusted these parameters depending on the modified product category and their expected release profiles throughout the product life cycle. We used three kinds of data sources: specific parameters reported in the peer-reviewed literature, analogous assumptions to similar product matrix constitution and applications as well as worst-case estimates. In table S1 of the Supporting Information the applied transfer coefficients are shown. The main product categories are elastomers, detergents and cosmetics, carrier materials (animal food), polymer and plastics as well as silicone elastomers.

Precipitated nano-silica is used in car tires as the main application in the product category "elastomers", which made up $40 \%$ of the total production volume. Nano-silica substitutes carbon black by $5-15 \mathrm{w} / \mathrm{w} \%$ for improving the rolling friction and reducing fuel consumption ${ }^{53,54}$ and the highest share has been applied as a worst-case assumption. During the product lifespan of typically four to six years, approximately $10-20 \%$ of the tire (here assumed as average of $15 \%$ ) is worn off during the use phase ${ }^{55}$. Tire dust can be resuspended to the atmosphere, which is usually difficult to determine. So far no studies are available that have specifically investigated the resuspension of nano-silica from road dust or in general the release of nano-silica from car tires. However, recent studies have shown that the road dust present in the air consists out of $10 \%$ tire dust as it was shown in the study of Harrison et al. ${ }^{56}$ for nonexhaust traffic particles, which is why we assumed the atmospheric release of tire dust containing nanosilica accordingly as a worst-case estimate. The remaining worn-off particles are released to both the sealed road and to the run-off (transferred to wastewater), as well as to the soil in the surroundings of the roads. Although some European roads (motorways) may have local rainwater treatments and consequently are not connected to the sewage network, further differentiation was not possible due to lack of data. A possible solution would be to relate the released fractions to the share of streets and highways in terms of $\mathrm{km}$ at an European level, but this is aggravated due to due to the inconsistent definitions of reported roads in European countries ${ }^{57}$. Additionally the diverse run-off water treatments (including no treatment, on site treatment and storage as well as transfer to the municipal WWTP) of rain run-offs in each European country is not known to the best of the authors knowledge, which would be needed to make a profound distribution of the $\mathrm{SiO}_{2}$ fractions released in tire dust.

In order to consider this environmental release pathway we assumed an equal distribution of the releases of tire dust to wastewater and soil as a first estimate. The end-of-life statistics were retrieved from the report of the European Tire \& Rubber manufacturers' association considering the European geographical scale ${ }^{58}$. In our model secondary fragmentation is not considered, although we are aware that such processes may release different percentage of fillers from tire wear depending on the fate on the road or in the sewer ${ }^{59}$.

Detergents and cosmetics is the second largest product category. Here, we used the assumed release factors provided by Wang et al. ${ }^{24}$ and specified the category according to five available cosmetic categories skin care, hair care, makeup, fragrance and personal hygiene based on their corresponding 
market share ${ }^{60}$. While the potential releases from makeup products were assumed to be transferred to WIP, other cosmetic subcategories are likely released to the wastewater stream after washing in consumer bathrooms.

Precipitated nano-silica is used as carrier materials and anti-caking agent in fertilizers in the context of agricultural soil treatment and this application represented the third most relevant application. The complete release to soil can be expected due to the intended application. Furthermore, precipitated nanosilica is used as an additive in polymers and plastics improving the mechanical properties of composites. The same transfer coefficients were assumed as done by Wang et al. ${ }^{24}$, who improved the assumptions and expert opinions used by Sun et al. ${ }^{13}$. Another relevant category in terms of production volume is silicone elastomers (i.e. fumed silica) that are applied in several application contexts such as automotive, machinery and construction. The release factors were based on Wang et al. ${ }^{24}$ for the EOL phase for sealants. The estimated releases during the use phase were based on Tolls et al. ${ }^{61}$, who specifically estimated the potential emissions/releases of adhesives and sealants.

Wastewater and solid waste streams are considered as the major environmental input flows (except if direct environmental releases occur). Both streams can be handled in respective technical compartments. Theoretically, each nano-silica species can have a different fate and behavior in such compartments and a more thoroughly differentiation would be useful in terms of a specific environmental risk assessment. The data on nano-silica behavior is sparse regarding the differentiation of silica species. However, we attempted to use the most recent and accessible data available in the literature. The selected approach for modeling the WWTP removal efficiency was used as described by Wang et al. ${ }^{24}$, who based their estimates on several experimental studies that were reported in the scientific literature. A differentiation of the removal efficiency for different silica species was not possible due to the lack of corresponding studies.

WIPs are characterized by high combustion temperatures in the range from $850^{\circ} \mathrm{C}$ to $1150^{\circ} \mathrm{C}{ }^{62}$. One available studies that analyzed metal (oxides) in full-scale WIP focused on ceria nanoparticles, which have a comparably high melting temperature ${ }^{63,64}$. Paur et al. ${ }^{65}$ have shown for nano-silica (and other ENMs) that these results can be transferred to large scale hazardous WIPs plants. Even though no studies on combustion of car tires containing nano-silica are available so far, it can be expected that nano-silica will similarly behave as nano-ceria due to its high melting temperature. We analogously expect persistence of silica when car tires are used as fuel in the large rotary kilns of klinker production.

Presently, landfills are seen as final sinks in current environmental material flow models due to the lack of corresponding data on potential leaching. Studies that investigated the leaching behavior are rare ${ }^{66}$, but they concluded that solid waste with its silicate glass matrix is a highly efficient filter and minimizes the leaching potential for nano- $\mathrm{ZnO}$ and nano- $\mathrm{TiO}_{2}{ }^{67}, 68$. Accordingly, we assumed the landfill as a final sink for (nano)silica in our model. 


\section{Results}

\section{Comparison of reported nanomaterials and bulk materials amounts}

The production volumes of substance-related market reports (GDP-scaled) and the French nanomaterial repository were compared for eight different nanomaterials as it is depicted in Figure $1^{33,45}$. The results are grouped into two categories for facilitating a clear presentation of the results and discussion:

1. The quantity of all forms of this substance is equal to the nanomaterial quantity within a range of less than factor 10 (category I)

2. The quantity of all forms of this substance is clearly larger than the nanomaterial quantity (category II)

(Nano)materials that belong to the "category l" are diketo-pyrrolo-pyrrole-based pigments (DPP, better known as Pigment Red 254) and silica $\left(\mathrm{SiO}_{2}\right)$ showing similar reported market volumes in both considered references with a match of $100 \%$ and $130 \%$ respectively (see absolute numbers in Table 2 ). The results for silica and DPP are reasonable since both materials are produced in the sub-micron scale and became newly defined as nanomaterials ${ }^{40,69}$.

Additionally, there are substances featuring a less perfect match, but still a reporting a very significant share of the total production (GDP-scaled) as nanoform production: A prominent example is given by carbon black (CB) with approximately $62 \%$ in the nanomaterial/total material comparison. The production of $\mathrm{CB}$ is based on a pyrolysis process having a high affinity to form bigger aggregates consisting of smaller constituent particles ranging from a few to some hundred nanometers ${ }^{70}$. Depending on the size distribution, CB can be classified as nano-product or as bulk depending on the defined grades and applied nanomaterial definition. Consequently, the French registration likely could have not recorded all CB grades due to the applied definition in year 2013, which would be a reasonable explanation for the obtained result for $\mathrm{CB}$. Eight of ten groups of rubber-grades of $\mathrm{CB}$ are specified with particle sizes below $100 \mathrm{~nm}$, and rubber accounts for $91 \%$ of the consumption of $C B{ }^{48}$.

Further substances with significant $(>10 \%)$ share of the production in nanoform include two more organic pigments, namely Pigment Red 48:2 (azo chemistry, 23.9\% nanoform) and Pigment Blue 15, Green 7 (Cu-Phtalocyanin), which is even more evident in the reporting of 2015 and 2016. This finding is easily rationalized: Organic pigments are offered in "opaque" (light-scattering) grades and in "transparent" (non-scattering) grades, the latter being essential for coatings with metallic reflections. The size of a pigment is intrinsically related to the wavelength of light, and optimization for high or low scattering effectiveness requires nanoparticles ("transparent" grades) or non-nano-materials ("opaque" grades). The organic pigments and $\mathrm{CB}$ are thus also assigned to category I, keeping in mind that not the entire production is in nanoform due to optimization of performance. 


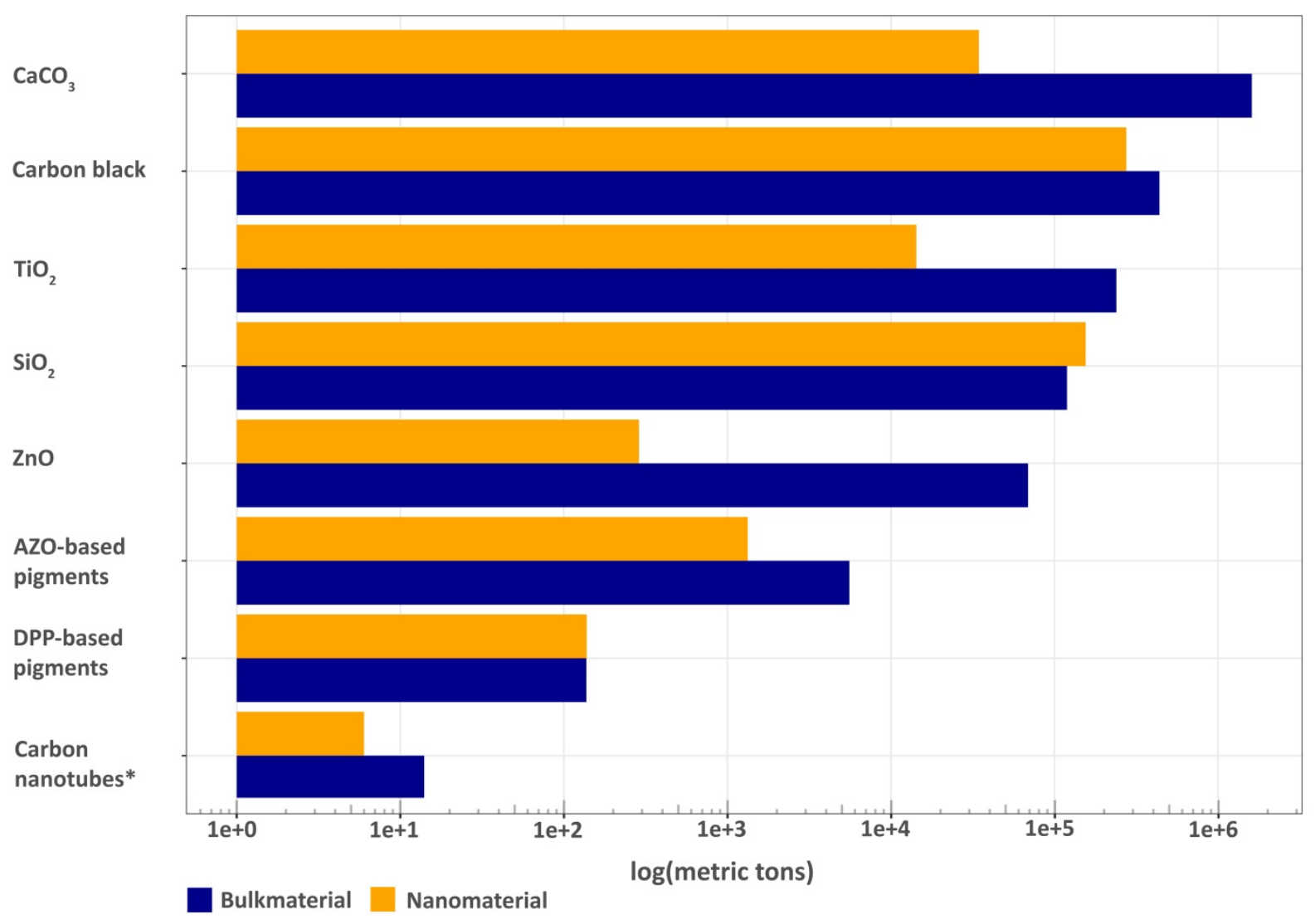

Figure 1. Comparison of reported nanomaterial production volumes in France for 2013 (orange) and the production of bulk materials (blue; scaled from the World production to France using the GWP/GDP). *The selected reference year is 2015

The materials considered in category II only have a share below $10 \%$ in nanoform. For ZnO only $0.4 \%$ are nano, for $\mathrm{CaCO}_{3} 2.1 \%$ and for $\mathrm{TiO}_{2} 6 \%$. The ANSES reports of $2015^{41}$ and $2016^{42}$ contain further materials with reporting of a very small share (less than $0.1 \%$ ) of a very large total production: globally, Kaolin is produced in 28 million metrics tons, and PVC ("Copolymère de chlorure de vinylidène" and "Polychlorure de vinyle") is produced in 38 million metric tons. All these materials are traditionally applied in highly established applications that do not benefit of small particles, specifically $\mathrm{ZnO}$ as vulcanization catalyst for elastomers, $\mathrm{TiO}_{2}$ as white pigments (requiring an optimal size around $200 \mathrm{~nm}$ for effective light scattering), and $\mathrm{CaCO}_{3}$ as filler in paper to reduce the consumption of cellulose, and Kaolin as paper gloss coating or filler in ceramics and plastics ${ }^{71}$. Some grades, however, may serve specific needs that require nanomaterials, e.g. the production of nanomaterial $\mathrm{ZnO}$ and $\mathrm{TiO}_{2}$ as transparent $\mathrm{UV}$ absorbers (nano- $\mathrm{TiO}_{2}$ being approved in the $\mathrm{EU}$, nano- $\mathrm{ZnO}$ being approved in Australia); another minor share of $\mathrm{TiO}_{2}$ can be attributed to the use in nanoform as photocatalyst, but is obviously marginal compared to the total production. Fine-ground and precipitated $\mathrm{CaCO}_{3}$ is used as filler and extender in a variety of applications, including paper, paint, plastics, adhesives, where the size, shape and specific surface area are relevant properties. Some grades feature BET surface areas up to $120 \mathrm{~m}^{2} / \mathrm{g}$, which is clearly a nanomaterial, but most grades have far lower specific surfaces and sizes from $2 \mu \mathrm{m}$ to $50 \mu \mathrm{m}$, identified as non-nano-materials ${ }^{26}$. Kaolin may have thin platelet thickness as identified by the NanoDefine project, but Kaolin is a special case because it is not manufactured but mined as natural material, and thus exempted from reporting in France ${ }^{72}$. 
Carbon nanotubes (CNT) are another exception and do not fit into either category. The CNT production based on the French register was only $43 \%$ of the market report data. Although CNTs clearly are nanomaterials by their diameter and by the derogation of the EC definition, the data selected from the market reports may include some speculative nuances particularly with regard to carbonaceous materials (CNTs and graphene) to which high expectations are associated ${ }^{73}$. Consequently, the production volumes in market reports can have a bias towards higher tonnages, which has to be interpreted carefully as for example companies such as Bayer withdrew from the CNT business in $2013^{74}$. Finally, it has to be considered that CNT production relies on much fewer producers than other materials, and their regional granularity that may not be adequately captured by the scaling of global production by French GDP. In this perspective, the match between reported nanoform production and total production is considered as compatible with the expectation that all CNTs are nanomaterials, consistent with the derogation of the EC definition. Regardless of the exact CNT production volume, it is evidently four or five orders of magnitude less than the nanoform production of silica and CB. 
Table 2. Comparison of French production or import in nanoform based on the nano-register with volumes downscaled from World production values of all forms of the same substance in 2013.

\begin{tabular}{|c|c|c|c|c|c|}
\hline Material & $\begin{array}{l}\text { all forms (France) } \\
\text { [metric tons/year] }\end{array}$ & Reference & $\begin{array}{l}\text { nanoforms (France) } \\
\text { [metric tons/year] }^{33}\end{array}$ & Reference & $\begin{array}{c}\text { Ratio Nano/Bulk } \\
{[\%]}\end{array}$ \\
\hline $\mathrm{CaCO}_{3}$ & 1'600'000 & $\begin{array}{c}\text { (Wietlis- } \\
\text { bach et al. } \\
2014)^{49}\end{array}$ & $34 ’ 501$ & \multirow[t]{8}{*}{$\underset{33}{(\text { Anses 2013) }}$} & 2.1 \\
\hline Carbon black & $438^{\prime} 000$ & $\begin{array}{l}\text { (Chinn et } \\
\text { al. 2014) } \\
\end{array}$ & $274^{\prime} 837$ & & 62.7 \\
\hline $\mathrm{TiO}_{2}$ & $2399^{\prime} 000$ & $\begin{array}{l}\text { (Wietlis- } \\
\text { bach et al. } \\
2014)^{44}\end{array}$ & $14^{\prime} 300$ & & 6 \\
\hline $\mathrm{SiO}_{2}$ & $119^{\prime} 000$ & $\begin{array}{l}\text { (Glauser et } \\
\text { al. 2014) }\end{array}$ & $155^{\prime} 000$ & & 130 \\
\hline $\mathrm{ZnO}$ & $69^{\prime} 000$ & $\begin{array}{l}\text { (Glauser et } \\
\text { al. 2014) }\end{array}$ & 288 & & 0.4 \\
\hline $\begin{array}{l}\text { AZO-based } \\
\text { pigments }\end{array}$ & $5^{\prime} 600$ & $\begin{array}{c}\text { (Linak et al. } \\
2015)^{50}\end{array}$ & 1'330 & & 23.9 \\
\hline $\begin{array}{l}\text { DPP-based pig- } \\
\text { ments }\end{array}$ & 137 & $\begin{array}{l}\text { (Smithers } \\
\text { Rapra } \\
2014)^{46}\end{array}$ & 138 & & 101 \\
\hline Carbon nanotubes* & $14^{*}$ & $\begin{array}{l}\text { (Lux Re- } \\
\text { search } \\
2016)^{47}\end{array}$ & 6 & & 42.9 \\
\hline
\end{tabular}

*Reference year 2015; ${ }^{* *}$ rounded to two to three significant digits

However, if we follow this two-fold categorization and its implications, two aspects have to be considered with regard to the modification of product categories and the allocation of production volumes in MFA modeling. Whilst category II materials comprise novel nano-specific and conventional applications that each require differently optimized materials (with different particle size), category I materials were always to a large extent or even dominating extent in the nanometer-range and were accordingly present as ENMs even before the term was introduced. Therefore, product applications of the category I likely do not differ between what is reported for conventional materials and based on the new "nano-identification", although new applications cannot be excluded. This implies that conventional product categories can be used to distribute the produced mass to products. As an example, we have chosen nanosilica to recalculate the material flows and present the results in the following sections.

\section{Silica/nano-silica material flow modeling}

The total European production volume was assumed with $459^{\prime} 000\left( \pm 93^{\prime} 000\right)$ metric tons of silica (equal to "nano-silica") in the reference year based on the market report by Glauser et al. ${ }^{45}$. Also, based on the product allocation of silica, we were able to quantify the flows of silica to the subsequent compartments as it is shown in Figure 2. The production, manufacturing and consumption (PMC) compartment is the starting point of environmental releases during the life cycle of the considered product categories. The output of the PMC compartment is separated into twelve outflows into both technical and environmental compartments. The most relevant flows are towards the recycling/WMS compartment with 101 '000 metrics tons. The second relevant compartment is the WIP with 92' 800 metric tons. The third relevant compartment is the cement kiln that received 78'900 metric tons. Other relevant receiving compartments were the landfill (46'900 metric tons) and the direct releases to natural and urban soil (42'700 
metric tons), both defined as final sink. Via the wastewater path approximately 53 ' 600 metrics tons enter the WWTP for further treatment.

In total eight compartments were defined as final sinks, which means that no further transport of nanosilica in these compartments was assumed. The results of the PMFA calculation showed several sinks from which "recycling/WMS" and "landfill" were the most relevant technical compartments with a final share of $29.4 \%$ and $26.5 \%$, respectively, of the total produced amount. The cement kiln was the third relevant sink in which $17.2 \%$ of the total production volume ended up. Particularly, the cement kiln is fed by the product category "car tires/elastomers". In the end-of-life of car tires, a major fraction is transferred to cement plants for thermal treatment. Natural and urban soil was the most relevant receiving environmental compartment $(9.3 \%)$. Less important were the compartments sediments $(6.7 \%)$, sludge treated soil $(4.3 \%)$, export $(4.2 \%)$ and biowaste $(2.4 \%)$.

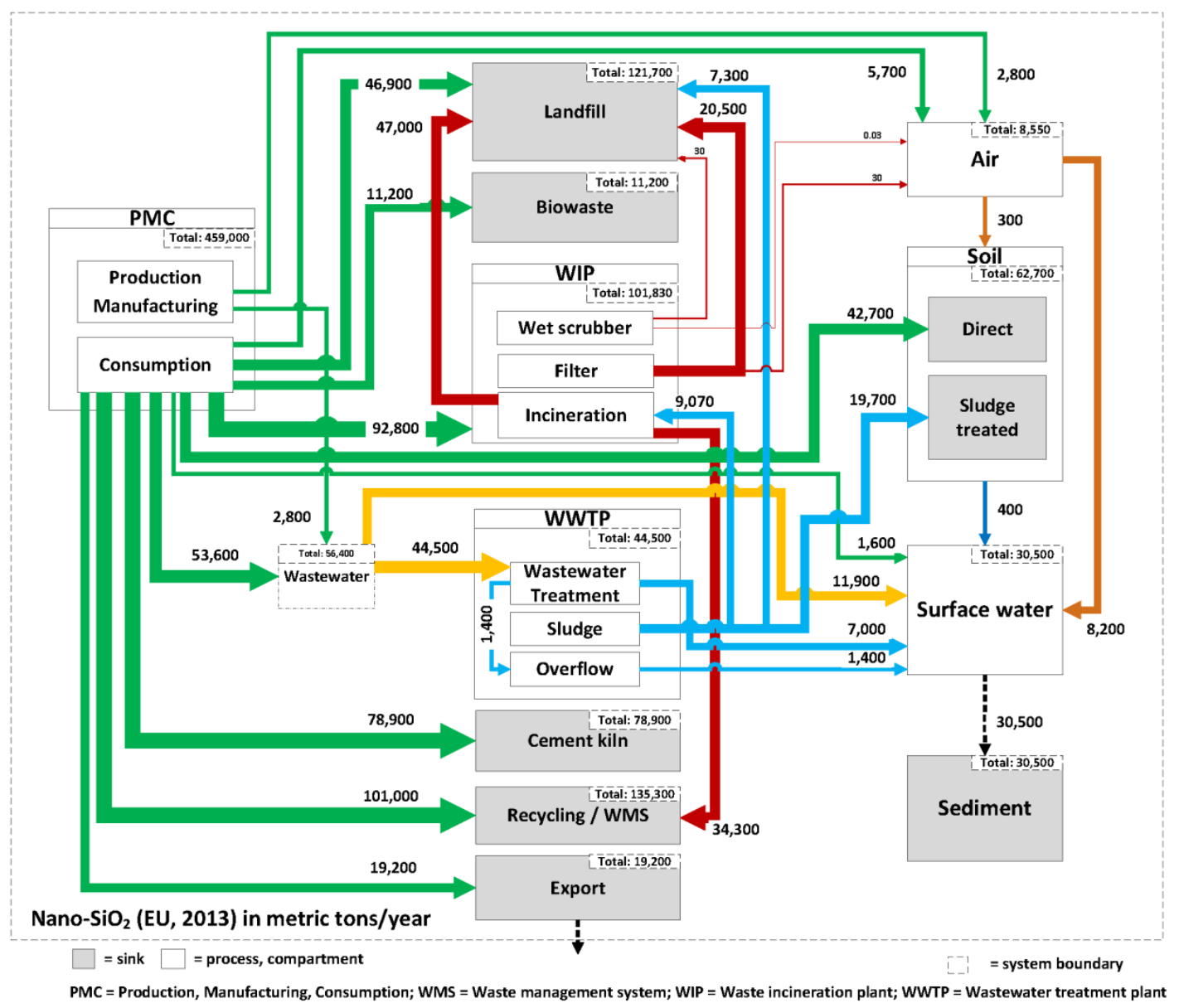

Figure 2. Mass-weighted nano-silica flows (mean values) from the PMC to technical and environmental compartments in European system boundaries and their total amounts received in 2013. Please note: the numbers are rounded to three significant digits. Therefore, the sum of the single compartments will not necessarily add up to the initial input of the system. 


\section{Predicted environmental concentrations of silica/nano-silica}

After determining the total amounts received per compartment, the PEC values for the environmental compartments can be derived. Here, we used the standard calculation procedure as shown in Sun et al. ${ }^{13}$ by dividing the total mass per compartment and its defined volume based on the Reach guidance 75. Thereby, a homogenous distribution of the released nano-silica is assumed for each compartment. Table 3 shows the modes, means as well as lower and upper quantile (i.e. $Q_{15}, Q_{85}$ ) for each environmental compartment considered. In comparison to the other PEC values, WWTP sludge and the application on to agricultural soil have the highest PEC with $4^{\prime} 000 \mathrm{mg} / \mathrm{kg}$ and $27 \mathrm{mg} / \mathrm{kg}$, respectively. In contrast, the $\mathrm{PEC}$ of the natural and urban soil compartment has a mean value of $83 \mu \mathrm{g} / \mathrm{kg}$ indicating to relatively high environmental direct releases as it is also shown in the material flow chart (cf. Figure 2). The surface water compartment has the lowest PEC value with a mean of $8.6 \mu \mathrm{g} / \mathrm{l}$, because of the high connection rate to the sewage network.

Table 3. Predicted environmental concentrations of nano-silica in Europe 2013 rounded to two significant digits.

\begin{tabular}{|c|c|c|c|c|c|}
\hline Compartment & $\mathbf{Q}_{\mathbf{1 5}}$ & Mode & Mean & $\mathbf{Q}_{\mathbf{8 5}}$ & Unit \\
\hline Sediments & 21 & 27 & 30 & 39 & $\mathrm{mg} / \mathrm{kg}$ \\
\hline Soil (N+U) & 62 & 79 & 83 & 100 & $\mu \mathrm{g} / \mathrm{kg}$ \\
\hline Sludge treated soil & $18^{`} 000$ & $24^{`} 000$ & $27^{`} 000$ & $35^{`} 000$ & $\mu \mathrm{g} / \mathrm{kg}$ \\
\hline Surface water & 6.1 & 7.7 & 8.6 & 11 & $\mu \mathrm{gg} / \mathrm{l}$ \\
\hline WWTP effluent & 60 & 68 & 240 & 440 & $\mu \mathrm{gg} / \mathrm{l}$ \\
\hline WWTP sludge & $2^{`} 800$ & $3^{`} 800$ & $4^{`} 000$ & $5^{`} 200$ & $\mathrm{mg} / \mathrm{kg}$ \\
\hline
\end{tabular}




\section{Discussion}

This study used the first legally required registration of ENM production (and import) amounts as well as market reports to predict the PEC for nano-silica. However, the results depend on several assumptions. These assumptions are related to the estimated production volume, the considered product categories and the PEC values calculated. In the following these three aspects will be discussed together with their limitations.

\section{Production volume estimation}

In general each mass-balance model depends on the selected input parameters, which is why these values are one of the most important for models. Here, the European production volume of silica/nanosilica was estimated with $459^{\prime} 000\left( \pm 93^{\prime} 000\right)$ metric tons/year (mean) on an annual basis based on the market report by Glauser et al. ${ }^{45}$. Compared to other state-of-the-art studies the estimated production volume is considerably higher. Wang et al. ${ }^{24}$ assumed for the mean input 91 '000 metric tons/year in Europe, which accounts for a five times lower amount compared to the here assumed volume. Wang et al. ${ }^{24}$ used and weighted different reported production volumes depending on the degree of belief of the source (i.e. a kind of quality and reliability score) stating a wide distribution. Likewise, Keller and Lazareva $(2013)^{76}$ used a commercially available market report estimating the production volumes for different regions in which the silica production was assumed to be mostly located in the U.S. with $50 \%$ of the world production. European producers only synthesized a fraction of $18 \%$ equal to $18^{\prime} 050$ metric tons/year ${ }^{76}$. This estimate is 25 times lower than the production volume of nano-silica that we estimate here.

Consequently, the key assumption is the derivation of the production volume. Uncertainties are expected both in the market reports and in the French registration system. In both cases the identification of a material as "nanomaterial" is challenging not only in terms of definition, but also by means of measurement by following the recommendation of the EC, now supported by the NanoDefine metrology ${ }^{27,77}$. Differences can arise thereby in the registration processes or reports. In the present article, we do not aim to identify wholesale substances as nanomaterials, and we do not aim to correct industry reporting to the French registration. Generally we conclude that some materials always contained nanoform grades to a smaller share of total production (such as metal oxides) whereas other substances were always produced in nanoform grades (probably predominantly in nanoform for $\mathrm{SiO}_{2}$, probably very significant shares in nanoform (roughly $50 \%$ or more) of $\mathrm{CB}$, organic pigments). The tonnages of the market report and the French registry corresponded within a thirty percent interval. A complete match likely will be not possible, because of the different underlying approaches for estimating the production volume. For instance, the French registry does not cover imported finished products but only the raw nanomaterials that were produced or imported to France. Also, it is difficult to derive general answers on the basis of national registries due to country-specific hotpots of industrial production. On the other hand, market reports depend on surveys and customer registers in which not only company biases can be reflected depending on the constitution of the interviewees so that even market reports differ in their market estimations, but also concrete customer data are included. Therefore, differences in the comparison of 
market reports and - in the case of this article - officially registered materials are unavoidable, but have to be taken into account.

It has to be noted that due to the applied scaling approach the results should be carefully interpreted due to the inherent uncertainties that each scaling approach has. Generally, upscaling aggregates local data by averaging them to a larger scale. Thereby, the upscaling of a local to global scale always has a loss of information while downscaling may not represent the local scale adequately ${ }^{78}$. The challenge is to find representative indicators that reflect the transformation of data. Data of each national economy and its production volume (including specific market shares of ENMs for the consumption) would be required to determine at least a range for potential production volumes or more specifically consumed amounts of ENMs. Commonly used indicators are based on economic indicators such as GDP, global domestic product - purchase power parity or inequality-adjusted human index ${ }^{13,16,76}$. Although these numbers may give the impression of being representative for a region, also limitations and shortcomings are discussed in the respective literature ${ }^{79,80}$. Therefore, our results should be interpreted as a first estimate and that's why the initial input parameter was modeled as a triangular distribution with an uncertainty range of \pm 50 percentage as described in the methods section.

However, the combination of both market reports and the French registry can give further and valuable prioritization of the actual exposure potential for nanomaterials, which should be used for environmental exposure assessments as long as no better information are available. For instance, materials such as CNTs, CuO or silver are among the most studied nanomaterials ${ }^{81}$ due to the expected hazard potential, whereas other materials have 10 '000 fold higher production in nanoform, and may eventually deserve more attention thereby shifting the focus to the exposure part of the risk assessment.

As another result of our cross-checking of nano-form registration vs. total production, the plausibility of registered tonnages increases, and contributes to reduce the uncertainties on consumer exposure that were highlighted in a recent ProSafe review. ${ }^{82}$

\section{Product categories and final sinks}

The final sinks for nano-silica predicted in our and in previous material flow models differ due to the new allocation to different product categories. Wang et al. ${ }^{24}$ identified the landfill and recycling/WMS as the most relevant compartment with $37.6 \%$ and $38.4 \%$ share of the total fraction respectively, which is slightly higher compared to our results with $26.5 \%$ for landfill and $29.4 \%$ for recycling/WMS. Furthermore, Wang et al. ${ }^{24}$ allocated only $4 \%$ of the production volume to the cement kiln, which was considerably less compared to our calculated fraction of $17.2 \%$. Likewise, the calculated share of the natural and urban soil compartment of $13.7 \%$ is almost twice as much than the results of Wang et al. ${ }^{24}$. Elastomers are the main contributing application for this difference in the cement kiln and soil compartment that constitute approximately $41 \%$ of the total production volume of nano-silica. The market report indicated that the most relevant use of elastomers is in car tires. The transfer coefficients were chosen accordingly based on a report by the industry association on end-of-life car tires including comprehensive data on collection rates and subsequent treatments ${ }^{58}$. The applied transfer coefficients should have an adequate quality with regard to geographical resolution and EOL processing steps. The study of Keller et al. ${ }^{5}$ identified a similar share of nano-silica $(11.2 \%)$ for the soil compartment at a global scale, whereas 
the majority of nano-silica ended up at landfills (85.5\%). The water and air compartment were less relevant with $2.2 \%$ and $1.1 \%$ at a global scale.

It can be noted that the results of the Wang et al. ${ }^{24}$ and Keller et al. ${ }^{5}$ and our study vary a lot regarding the final sinks and their receiving fractions of nano-silica because of two main reasons. First, Keller et al. ${ }^{5}$ investigated the mass flows at a global scale and since the national WMSs differ quite a lot ${ }^{15,39,83}$, bigger fractions are most likely transferred to the landfill at global scale, which is in most European countries strongly regulated and prohibited. Second, both studies used other product categories than our study. In general, the information on product categories entailing incorporated ENMs is scarce and if, only in very limited access available. So far, product categories were compiled by patent databases, Internet queries or specific market reports on a less detailed level as we have done it in this article, whereas the here presented product categories were based on one market report that seemed to have a reliable background due to the matching of the production amounts. Also, as Adam and Nowack ${ }^{39}$ pointed it out, the product categories should be defined in a way that product-specific life cycles can be assessed in MFAs. Here, the product categories are regarded in more detail; however, one assumption in this article is that the product category "elastomers" mainly consists of car tires, even though other elastomers can be used in varying application contexts that may lead to quite different exposure scenarios. It is reasonable to attribute the strong growth of elastomer grades of precipitated silica from 130,000 metric tons (EU in 1995) to 220,000 metric tons (EU in 2013) to the newly developed "HD" (highly-dispersible) silica grades required for tires ${ }^{45,54}$. During this time, all precipitated silica grades grew from 223,000 to 347,000 metric tons. The identification of elastomers with tire rubber should be interpreted as worst-case since car tires have a comparably high and in particular direct environmental release potential due to abrasion during use.

The consideration of conventional product categories as "nano-products" can have another drawback. On the one hand, it is likely that due to the use of nanomaterials new products enter the market that do not fit to the conventional product categories by having different release profiles and subsequently different environmental exposures. On the other hand, the main applications of nano-silica mainly included dispersed nanomaterials or sintered composites leading to a group of similar release and exposure scenarios, so far. As long as no disruptive innovation changes the types of products, the release profiles may not change dramatically, but shift to one or the other category.

\section{Predicted environmental concentrations}

One of the main reason for the differences in PEC values between our study and previous estimates is the 5-25 times higher production volume compared to Wang et al. (2016) ${ }^{24}$ and Keller et al. (2013) ${ }^{5}$, respectively. Table 4 lists the different mean PEC values of the three available studies. In general compared to Wang et al (2016) ${ }^{24}$ most of the compartments considered have an approximately 4 to 4.5 times higher PEC value, which is in the same order of magnitude of the production volume increase. One exception is the natural and urban soil compartment with an approximately 13 times higher PEC of $83 \mu \mathrm{g} / \mathrm{kg}$ compared to $6.2 \mu \mathrm{g} / \mathrm{kg}^{24}$.

The study of Keller et al. $(2013)^{5}$ estimated a PEC for WWTP effluents in the range of 0.1 to $10 \mu \mathrm{g} / \mathrm{l}$ and for WWTP sludge (bio-solids) in the range of 10 to $100 \mathrm{mg} / \mathrm{kg}$ for the U.S., which is considerably lower 
compared to our calculated values. Despite the considered geographical area may have an influence on the results, an earlier study has shown that comparable PEC values can be expected for both geographical areas ${ }^{52}$.

Table 4. Comparison of PEC values calculated in different studies on nano-silica for the European Union rounded to two significant digits *.

\begin{tabular}{|c|c|c|c|c|}
\hline $\begin{array}{l}\text { Environmental } \\
\text { compartment }\end{array}$ & $\begin{array}{c}\text { This } \\
\text { study } \\
\text { (mean) }\end{array}$ & $\begin{array}{l}\text { Wang et al. } \\
(2016)^{24} \\
\text { (mean) }\end{array}$ & $\begin{array}{l}\text { Keller et al. } \\
(2013)^{5}\end{array}$ & $\begin{array}{c}\text { Wang and Nowack } \\
(2018) \\
\text { (mean - year 2014) }\end{array}$ \\
\hline $\begin{array}{l}\text { Sediments } \\
{[\mathrm{mg} / \mathrm{kg}]}\end{array}$ & 30 & 6.7 & $\mathrm{n} / \mathrm{a}$ & 79 \\
\hline $\begin{array}{c}\text { Soil }(N+U) \\
{[\mu g / k g]}\end{array}$ & 83 & 6.2 & $\mathrm{n} / \mathrm{a}$ & 86 \\
\hline $\begin{array}{c}\text { Sludge treated } \\
\text { soil }[\mu \mathrm{g} / \mathrm{kg}]\end{array}$ & $27^{\prime} 000$ & 6’300 & $\mathrm{n} / \mathrm{a}$ & $150 ' 000$ \\
\hline $\begin{array}{c}\text { Surface water } \\
{[\mu \mathrm{g} / \mathrm{l}]}\end{array}$ & 8.6 & 1.9 & $\mathrm{n} / \mathrm{a}$ & 4.3 \\
\hline $\begin{array}{c}\text { WWTP effluent } \\
{[\mu \mathrm{g} / \mathrm{l}]}\end{array}$ & 240 & 56 & $\sim 0.1-10$ & 65 \\
\hline $\begin{array}{c}\text { WWTP sludge } \\
{[\mathrm{mg} / \mathrm{kg}]}\end{array}$ & 4‘000 & 940 & $\sim 10-100$ & 44400 \\
\hline
\end{tabular}

Two main reasons can be considered for the differing PEC values. First, the detailed investigation of product categories identified 30 applications of which 22 product uses are released via the wastewater pathway, whereas in the other papers the main pathways were the solid waste stream leading to incineration. Due to the relatively high connectedness and removal efficiency of WWTPs, most of the fraction settles down in the WWTP sludge that is being used as fertilizer in most of the European countries. Second, as shown in Figure 2, only a minor fraction of nano-silica is transferred to the sludge treated soil compartment. However, because of the smaller defined volume compared to other compartments, the input flows have a higher influence on the PEC values leading to this considerable increase.

However, compared to the study of Wang and Nowack only minor differences can be identified, except for the sludge treated soil compartment in which a five times higher concentration was calculated. The reason for this difference is the assumptions about the production volumes and product categories resulting in a release into wastewater. However, it is generally difficult to compare static models with dynamic models. Generally, dynamic models attempt to cover also temporal aspects by considering stocks that may result into a delayed release and into peaks of environmental concentrations. The reason for considering temporal aspects is the time-dependence of environmental releases and exposures, which are linked to the service life of products (i.e. for MFA models) and the degradation mechanisms that may occur in environmental media ${ }^{84}$. The system considered is never in a steady-state condition. As a result, recent studies have shown that the accumulation of ENMs in use-stocks (i.e. products that may be disposed of at later period of time) likely lead to a delayed release in the end-of-life stage ${ }^{16-18}$.

In context of dynamic modeling it is known that the increase of production capacities (or volume) will not drastically change over time as long as the products (or the single substances) are established on the market ${ }^{85}$. Consequently, the increase of production per period of time will have a smaller release potential than the accumulation in-use stocks over a longer timeframe. A dynamic modeling is only recommended for novel products entering the market where no steady-state has been reached ${ }^{84,}{ }^{85}$. In the case of (nano)silica our results have shown that established applications embedding (nano)silica are in 
use for a longer period of time and thus a quasi-steady-state equilibrium can be assumed. Of course, the results should be interpreted as a snapshot of the system, which may change when disruptive innovations will enter the market in the future leading to different releases and concentrations.

When using the term "predicted environmental concentration", we need to keep in mind that we did not calculate PEC values for a real environment but for a standard region as defined in the REACH guideline

75 . The numbers represent worst-case assumptions neglecting any further transformations or fate of the ENM. Such transformations may include heteroagglomeration as well as sedimentation, which strongly depends on the constitution of (nano)silica debris and surrounding environmental media. Under normal environmental conditions pristine silica behaves as an inert material ${ }^{86}$. In aquatic environments a certain dissolution of (nano)silica can be expected ${ }^{86}$. Al-Kattan et al. concluded in their study on weathering of (nano)silica paints that dissolution is a relevant mechanism leading to an environmental release of silica ${ }^{87}$. Nevertheless, environmental fate and behavior studies are still needed to determine the final transformations of released (nano)silica ${ }^{88,89}$. Additionally, it has to be noted that local hot spots can occur depending on the point source and the environmental context, which can lead to higher or lower concentrations as shown by others ${ }^{90,91}$. Our mass flow values will provide fate models such as those developed by Meesters et al. (2014) ${ }^{92}$ and Garner et al. $2017^{14}$ the required input values that can be used to derive local PEC values and including relevant environmental fate processes.

\section{Conclusions}

MFA and environmental fate models rely on the data on the ENM production volumes and its allocation to product categories comprising two major determinants in current modeling approaches. Some European countries have introduced a mandatory registration of ENMs as for instance France, Belgium, Norway and Denmark. As a result, some conventional materials became identified as nanomaterial due to the definition by particle size without respect to novelty or other properties. This article aimed to combine two data sources separately per chemical substance: the French repository provides production volumes in nanoform and market reports on that substance give insights to total production volumes and potential product categories. Consequently, we compared the French registry data of 2013 - which remains consistent in the 2016 reports - with geographically down-scaled market reports in order to identify potential relabeled materials by matching tonnages and to be able to use more detailed data on product applications. Most of the considered materials, especially $\mathrm{Fe}_{2} \mathrm{O}_{3}, \mathrm{ZnO}, \mathrm{TiO}_{2}, \mathrm{CaCO}_{3}$, showed comparably large differences (more than one, often three orders of magnitude) between the two approaches to production volumes, indicating that the nanoform serves a distinct purpose that is required only for a smaller share of the market. This may or may not be a novel purpose. However, for some materials the French registration and market reports of all forms of this substance agree, indicating that no distinction can be made between "conventional" and "nanoform"; we further took this matching as evidence that likely no novel nano-applications exist but that conventional product categories are likely the main application of the nanoforms, although novel applications may be included or will appear in the future.

Especially nano-silica was identified as such a "conventional nanomaterial", but also organic pigments and $\mathrm{CB}$. We have remodeled the PEC values for nano-silica/silica based on the newly gained 
information regarding the potential production volume and product categories. It was shown that nanosilica is very likely present in amounts up by a factor of five in environmental compartments compared to previous studies. Besides of the higher production volume, the results were driven by the application elastomers comprising almost the half of the total production volume. According to the market report, the main application of elastomers is car tires that are characterized by their direct environmental releases to soil and wastewater compartment affecting the PEC values accordingly. Due to the high relevance of this application further experimental work would be needed to confirm or to prove false this observation, and to trace the secondary degradation and transformation after the primary release event. Future environmental risk assessments ought to specifically consider both applications with a high production volume and/or with direct environmental releases. In doing so, data and information on conventional bulk materials can be used as starting point for prioritizing research and risk assessments.

\section{Acknowledgements}

The authors declare no conflict of interest. This work was financed by caLIBRAte which has received funding from the European Union's Horizon 2020 Research and Innovation Programme under Grant Agreement 686239 (H.W.). Partial support was received from the NanoDefine project under FP7 Grant Agreement 604347 (W.W.). The authors acknowledge Delphine Wenger's help in the development of the code necessary for this model. 


\section{References}

1. ISO/TS 80004-2, Nanotechnologies vocabulary International Organization for Stanardization, Geneva, Switzerland, 2015.

2. W. Wohlleben, C. Punckt, J. Aghassi-Hagmann, F. Siebers, F. Menzel, D. Esken, C.-P. Drexel, H. Zoz, H. U. Benz, A. Weier, M. Hitzler, A. I. Schäfer, L. D. Cola and E. A. Prasetyanto, in Metrology and Standardization for Nanotechnology: Protocols and Industrial Innovations, eds. E. Mansfield, D. L. Kaiser, D. Fujita and M. Van de Voorde, John Wiley \& Sons, 2017, pp. 411464.

3. W. Stark, P. Stoessel, W. Wohlleben and A. Hafner, Industrial applications of nanoparticles, Chemical Society Reviews, 2015, 44, 5793-5805.

4. F. Gottschalk and B. Nowack, The release of engineered nanomaterials to the environment, Journal of Environmental Monitoring, 2011, 13, 1145-1155.

5. A. A. Keller, S. McFerran, A. Lazareva and S. Suh, Global life cycle releases of engineered nanomaterials, Journal of Nanoparticle Research, 2013, 15:1692, 1-17.

6. T. Y. Sun, N. A. Bornhoft, K. Hungerbuhler and B. Nowack, Dynamic probabilistic modeling of environmental emissions of engineered nanomaterials, Environmental Science \& Technology, 2016, 50, 4701-4711.

7. IPCS, International programme on chemical safety (IPCS Harmonization Project) - Risk assessment terminology, WHO, Geneva, 2004.

8. B. Nowack, Evaluation of environmental exposure models for engineered nanomaterials in a regulatory context, Nanolmpact, 2017, 8, 38-47.

9. A. B. Boxall, Q. Chaudhry, C. Sinclair, A. Jones, R. J. Aitken, B. Jefferson and C. Watts, Current and future predicted environmental exposure to engineered nanoparticles, 2007.

10. N. Müller and B. Nowack, Exposure modeling of engineered nanoparticles in the environment, Environmental Science \& Technology, 2008, 42, 4447-4453.

11. R. Arvidsson, S. Molander and B. A. Sandén, Particle Flow Analysis, Journal of Industrial Ecology, 2012, 16, 343-351.

12. F. Gottschalk, R. W. Scholz and B. Nowack, Probabilistic material flow modeling for assessing the environmental exposure to compounds: Methodology and an application to engineered nano-TiO2 particles, Environmental Modelling \& Software, 2010, 25, 320-332.

13. T. Y. Sun, F. Gottschalk, K. Hungerbuhler and B. Nowack, Comprehensive probabilistic modelling of environmental emissions of engineered nanomaterials, Environmental pollution, 2014, 185, 69-76.

14. K. L. Garner, S. Suh and A. A. Keller, Assessing the Risk of Engineered Nanomaterials in the Environment: Development and Application of the nanoFate Model, Environmental Science \& Technology, 2017, 51, 5541-5551.

15. H. Wigger, S. Hackmann, T. Zimmermann, J. Koser, J. Thoming and A. von Gleich, Influences of use activities and waste management on environmental releases of engineered nanomaterials, The Science of the total environment, 2015, 535, 160-171.

16. Y. Wang and B. Nowack, Dynamic probabilistic material flow analysis of nano-SiO2, nano iron oxides, nano-CeO2, nano-Al2O3, and quantum dots in seven European regions, Environmental pollution, 2018, 235, 589-601.

17. R. Song, Y. Qin, S. Suh and A. A. Keller, Dynamic Model for the Stocks and Release Flows of Engineered Nanomaterials, Environmental Science \& Technology, 2017, 51, 12424-12433.

18. B. Giese, F. Klaessig, B. Park, R. Kaegi, M. Steinfeldt, H. Wigger, A. v. Gleich and F. Gottschalk, Engineered nanomaterials in Germany: Risks, release, and concentrations modeled and compared to measurements, Nature Scientific Reports, 2018, 8:1565.

19. T. Y. Sun, D. M. Mitrano, N. A. Bornhoft, M. Scheringer, K. Hungerbuhler and B. Nowack, Envisioning Nano Release Dynamics in a Changing World: Using Dynamic Probabilistic Modeling to Assess Future Environmental Emissions of Engineered Nanomaterials, Environmental Science \& Technology, 2017, 51, 2854-2863.

20. N. A. Bornhöft, T. Y. Sun, L. M. Hilty and B. Nowack, A dynamic probabilistic material flow modeling method, Environmental Modelling \& Software, 2016, 76, 69-80. 
21. F. Gottschalk, T. Sun and B. Nowack, Environmental concentrations of engineered nanomaterials: Review of modeling and analytical studies, Environmental pollution, 2013, 181, 287-300.

22. J. A. J. Meesters, J. T. K. Quik, A. A. Koelmans, A. J. Hendriks and D. van de Meent, Multimedia environmental fate and speciation of engineered nanoparticles: a probabilistic modeling approach, Environmental Science: Nano, 2016, 3, 715-727.

23. F. Piccinno, F. Gottschalk, S. Seeger and B. Nowack, Industrial production quantities and uses of ten engineered nanomaterials in Europe and the world, Journal of Nanoparticle Research 2012, 14, 1-11.

24. Y. Wang, A. Kalinina, T. Sun and B. Nowack, Probabilistic modeling of the flows and environmental risks of nano-silica, The Science of the total environment, 2016, 545-546, 67-76.

25. Ec, Commission Recommendation of 18 October 2011 on the definition of nanomaterial, 2011.

26. F. Babick, J. Mielke, W. Wohlleben, S. Weigel and V.-D. Hodoroaba, How reliably can a material be classified as a nanomaterial? Available particle-sizing techniques at work, Journal of Nanoparticle Research, 2016, 18, 1-40.

27. W. Wohlleben, J. Mielke, A. Bianchin, A. Ghanem, H. Freiberger, H. Rauscher, M. Gemeinert and V. D. Hodoroaba, Reliable nanomaterial classification of powders using the volume-specific surface area method, Journal of Nanoparticle Research, 2017, 19, 61.

28. P. Muller, J. Mielke, V.-D. Hodoroaba, R. Kagi and M. Ryner, Assessment of Different Electron Microscopy Techniques for Particle Size Quantification of Potential Nanomaterials, Microscopy and Microanalysis, 2015, 21, 2403-2404.

29. H. RAUSCHER, G. ROEBBEN, A. BOIX SANFELIU, H. EMONS, P. GIBSON, R. KOEBER, T. LINSINGER, K. RASMUSSEN, J. RIEGO SINTES, B. SOKULL-KLUETTGEN and H. STAMM, Towards a review of the EC Recommendation for a definition of the term "nanomaterial": Part 3: Scientific-technical evaluation of options to clarify the definition and to facilitate its implementation, JRC_95675, 2015, 1-34.

30. NEA, Duty to declare nanomaterials, http://www.miljodirektoratet.no/en/Areas-ofactivity1/Chemicals/The-Product-Register/Duty-to-declare/, (accessed November 2nd, 2017).

31. FPS, Nanoregistry, https://www.health.belgium.be/en/environment/chemicalsubstances/nanomaterials/register, (accessed November 2nd, 2017).

32. DEPA, Guideline for the Danish Inventory of Nanoproducts, Danish Environment Protection Agency, Copenhagen, Denmark, 2017.

33. ANSES, Éléments issus des déclarations des substances à l'état nanoparticulaire., ANSES (l'Agence nationale de sécurité sanitaire), Paris, France, 2013.

34. W. Wohlleben and N. Neubauer, Quantitative rates of release from weathered nanocomposites are determined across 5 orders of magnitude by the matrix, modulated by the embedded nanomaterial, Nanolmpact, 2016, 1, 39-45.

35. A. J. Koivisto, A. C. Ø. Jensen, K. I. Kling, A. Nørgaard, A. Brinch, F. Christensen and K. A. Jensen, Quantitative material releases from products and articles containing manufactured nanomaterials: Towards a release library, Nanolmpact, 2017, 5, 119-132.

36. H. Wigger, Environmental release of and exposure to iron oxide and silver nanoparticles prospective estimations based on product application scenarios, Springer Vieweg, Wiesbaden, Germany, 2017.

37. S. Foss Hansen, L. R. Heggelund, P. Revilla Besora, A. Mackevica, A. Boldrin and A. Baun, Nanoproducts - what is actually available to European consumers?, Environmental Science: Nano, 2016, 3, 169-180.

38. M. E. Vance, T. Kuiken, E. P. Vejerano, S. P. McGinnis, M. F. Hochella, D. Rejeski and M. S. Hull, Nanotechnology in the real world: Redeveloping the nanomaterial consumer products inventory, Beilstein J. Nanotechnol., 2015, 6, 1769-1780.

39. V. Adam and B. Nowack, European country-specific probabilistic assessment of nanomaterial flows towards landfilling, incineration and recycling, Environmental Science: Nano, 2017, 4, 1961-1973.

40. A. Bosch, M. Maier and P. Morfeld, Nanosilica? Clarifications are necessary!, Nanotoxicology, 2012, 6, 611-613.

41. ANSES, Éléments issus des déclarations des substances à l'état nanoparticulaire., ANSES (l'Agence nationale de sécurité sanitaire), Paris, France, 2015. 
42. ANSES, Éléments issus des déclarations des substances à l'état nanoparticulaire., ANSES (l'Agence nationale de sécurité sanitaire), Paris, France, 2016.

43. J. Glauser and S. Schlag, Chemical economics handbook - Inorganic zinc chemicals, IHS Markit, London, United Kingdom, 2014.

44. S. Wietlisbach, J. Glauser, C. Funada and A. Gao, Chemical economics handbook - Titanium dioxide, IHS markit, London, United Kingdom, 2014.

45. J. Glauser, S. Wietlisbach and C. Funada, Chemical economics handbook - Silcates and silicas, IHS markit, London, United Kingdom, 2014.

46. Smithers Rapra, The future of high performance and specialty pigments to 2019, Smither Rapra, USA, 2014.

47. Lux Research, Carbon materials - Update 2016, Lux Research, Boston, USA, 2016.

48. H. Chinn, M. Yoneyama and W. Chen, Chemical economics handbook - Carbon black, IHS markit, London, United Kingdom, 2014.

49. S. Wietlisbach, J. Glauser, C. Funada and A. Gao, Chemical economics handbook - Fineground and precipitated calcium carbonate, IHS markit, London, United Kingdom, 2014.

50. E. Linak, A. Kishi, M. Guan and U. Buchholz, Chemical economics handbook - pigments, organic color, IHS markit, London, United Kingdom, 2015.

51. TWB, Global domestic product (current US\$), (accessed October 12, 2017).

52. F. Gottschalk, T. Sonderer, R. W. Scholz and B. Nowack, Modeled environmental concentrations of engineered nanomaterials ( $\mathrm{TiO}(2), \mathrm{ZnO}, \mathrm{Ag}, \mathrm{CNT}$, Fullerenes) for different regions, Environmental Science \& Technology, 2009, 43, 9216-9222.

53. A. Wik and G. Dave, Occurrence and effects of tire wear particles in the environment-a critical review and an initial risk assessment, Environmental pollution, 2009, 157, 1-11.

54. OECD, Nanotechnology and Tyres Greening Industry and Transport, Paris, France, 2014.

55. M. Milani, F. P. Pucillo, M. Ballerini, M. Camatini, M. Gualtieri and S. Martino, First evidence of tyre debris characterization at the nanoscale by focused ion beam, Materials Characterization, 2004, 52, 283-288.

56. R. M. Harrison, A. M. Jones, J. Gietl, J. Yin and D. C. Green, Estimation of the contributions of brake dust, tire wear, and resuspension to nonexhaust traffic particles derived from atmospheric measurements, Environmental Science \& Technology, 2012, 46, 6523-6529.

57. EURF, Road statistics - Yearbook 2016, European Union Road Federation, Brussels, Belgium, 2016.

58. ETRMA, End-of-life Tyre Report, European Tyre and Rubber manufactures' Association (ETRMA), Brussels, Belgium, 2015.

59. W. Wohlleben, J. Meyer, J. Muller, P. Muller, K. Vilsmeier, B. Stahlmecke and T. A. J. Kuhlbusch, Release from nanomaterials during their use phase: combined mechanical and chemical stresses applied to simple and multi-filler nanocomposites mimicking wear of nanoreinforced tires, Environmental Science: Nano, 2016, 3, 1036-1051.

60. S. Kumar, Exploratory analysis of global cosmetic industry: major players, technology and market trends, Technovation, 2005, 25, 1263-1272.

61. J. Tolls, D. Gomez, W. Guhl, T. Funk, E. Seger and T. Wind, Estimating emissions from adhesives and sealants uses and manufacturing for environmental risk assessments, Integrated environmental assessment and management, 2016, 12, 185-194.

62. H. Forster, T. Thajudeen, C. Funk and W. Peukert, Separation of nanoparticles: Filtration and scavenging from waste incineration plants, Waste Management, 2016, 52, 346-352.

63. T. Walser, L. K. Limbach, E. Brogioli, F. Luca, B. Hattendorf, M. Juchli, F. Krumeich, C. Ludwig, K. Prikopsky, M. Rossier, D. Saner, A. Sigg, S. Hellweg, D. Günther and W. J. Stark, Persistence of engineered nanoparticles in a municipal solid-waste incineration plant, Nature nanotechnology, 2012, 7, 520-524.

64. A. M. Jones and R. M. Harrison, Emission of ultrafine particles from the incineration of municipal solid waste: A review, Atmospheric Environment, 2016, 140, 519-528.

65. H. R. Paur, W. Baumann, M. Hauser, I. Lang, N. Teuscher, H. Seifert and D. Stapf, Thermal Stability and Material Balance of Nanomaterials in Waste Incineration, Journal of Physics: Conference Series, 2017, 838. 
66. D. M. Mitrano, K. Mehrabi, Y. A. R. Dasilva and B. Nowack, Mobility of metallic (nano)particles in leachates from landfills containing waste incineration residues, Environmental Science: Nano, 2017, 4, 480-492.

67. M. Dulger, T. Sakallioglu, I. Temizel, B. Demirel, N. K. Copty, T. T. Onay, C. S. Uyguner-Demirel and T. Karanfil, Leaching potential of nano-scale titanium dioxide in fresh municipal solid waste, Chemosphere, 2016, 144, 1567-1572.

68. T. Sakallioglu, M. Bakirdoven, I. Temizel, B. Demirel, N. K. Copty, T. T. Onay, C. S. Uyguner Demirel and T. Karanfil, Leaching of nano-ZnO in municipal solid waste, Journal of hazardous materials, 2016, 317, 319-326.

69. O. Wallquist, in High performance pigments, ed. H. M. Smith, Wiley-VCH Verlag GmbH \& Co. KGaA, Weinheim, Germany, 2002, ch. 11, pp. 159-184.

70. T. A. Kuhlbusch and H. Fissan, Particle characteristics in the reactor and pelletizing areas of carbon black production, Journal of occupational and environmental hygiene, 2006, 3, 558-567.

71. A. Mehta, E. Woo and J. Iorillo, World Kaolin, The Freedonia Group, Cleveland, Ohia, U.S., 2012.

72. France, Decree no. 2012-232 of 17 February 2012 on the annual declaration on substances at nanoscale in application of article R. 523-4 of the Environment code.Journal, 2012.

73. T. K. Das and S. Prusty, Graphene-based polymer composites and their applications, PolymerPlastics Technology and Engineering, 2013, 52, 319-331.

74. PT, Bayer MaterialScience exits carbon nanotube business, https://www.plasticstoday.com/content/bayer-materialscience-exits-carbon-nanotubebusiness/97630387718802, (accessed September 29th, 2017).

75. ECHA, Guidance on information requirements and chemical safety assessment chapter R.16: Environmental exposure estimation.Journal, 2016.

76. A. A. Keller and A. Lazareva, Predicted releases of engineered nanomaterials: From global to regional to local, Environmental Science \& Technology Letters, 2013, 1, 65-70.

77. H. Rauscher, K. Rasmussen and B. Sokull-Klüttgen, Regulatory aspects of nanomaterials in the EU, Chemie Ingenieur Technik, 2017, 89, 224-231.

78. J. Wu and $\mathrm{H}$. Li, Perspectives and method of scaling, Scaling and Uncertainty Analysis in Ecology: Methods and Applications, 2006, DOI: 10.1007/1-4020-4663-4, 17-44.

79. H. Wolff, H. Chong and M. Auffhammer, Classification, detection and consequences of data error: evidence from the human development index, The Economic Journal, 2011, 121, 843870.

80. S. Seth and A. Villar, Measuring Human Development and Human Deprivations, Oxford Poverty \& Human Development Initiative, Oxford, United Kingdom, 2017.

81. K. Juganson, A. Ivask, I. Blinova, M. Mortimer and A. Kahru, NanoE-Tox: New and in-depth database concerning ecotoxicity of nanomaterials, Beilstein Journal of Nanotechnology, 2015, 6, $1788-1804$.

82. T. A. J. Kuhlbusch, S. W. P. Wijnhoven and A. Haase, Nanomaterial exposures for worker, consumer and the general public, Nanolmpact, 2018, 10, 11-25.

83. L. Heggelund, S. F. Hansen, T. F. Astrup and A. Boldrin, Semi-quantitative analysis of solid waste flows from nano-enabled consumer products in Europe, Denmark and the United Kingdom - Abundance, distribution and management, Waste Management, 2016, 56, 584-592.

84. OECD, Complementing Guideline for writing emission scenario documents: the life-cycle step "service life", Organisation for Economic Co-operation and Development, Paris, France, 2009.

85. OECD, Guidance document on the use of multimedia models for estimating overall environmental persistance and long-range transport, Organisation for Economic Co-operation and Development, Paris, France, 2004.

86. C. Fruijtier-Polloth, The toxicological mode of action and the safety of synthetic amorphous silica-a nanostructured material, Toxicology, 2012, 294, 61-79.

87. A. Al-Kattan, A. Wichser, R. Vonbank, S. Brunner, A. Ulrich, S. Zuin, Y. Arroyo, L. Golanski and B. Nowack, Characterization of materials released into water from paint containing nano-SiO2, Chemosphere, 2015, 119, 1314-1321.

88. S. Zuin, A. Massari, A. Ferrari and L. Golanski, Formulation effects on the release of silica dioxide nanoparticles from paint debris to water, Science of the total environment, 2014, 476 477, 298-307. 
89. B. Nowack, A. Boldrin, A. Caballero, S. F. Hansen, F. Gottschalk, L. Heggelund, M. Hennig, A. Mackevica, H. Maes, J. Navratilova, N. Neubauer, R. Peters, J. Rose, A. Schaffer, L. Scifo, S. van Leeuwen, F. von der Kammer, W. Wohlleben, A. Wyrwoll and D. Hristozov, Meeting the Needs for Released Nanomaterials Required for Further Testing-The SUN Approach, Environmental Science \& Technology, 2016, 50, 2747-2753.

90. F. Gottschalk, C. Ort, R. W. Scholz and B. Nowack, Engineered nanomaterials in rivers Exposure scenarios for Switzerland at high spatial and temporal resolution, Environmental pollution, 2011, 159, 3439-3445.

91. A. L. Dale, E. A. Casman, G. V. Lowry, J. R. Lead, E. Viparelli and M. Baalousha, Modeling nanomaterial environmental fate in aquatic systems, Environmental Science \& Technology, 2015, 49, 2587-2593.

92. J. A. Meesters, A. A. Koelmans, J. T. Quik, A. J. Hendriks and D. van de Meent, Multimedia modeling of engineered nanoparticles with SimpleBox4nano: model definition and evaluation, Environmental Science \& Technology, 2014, 48, 5726-5736. 